\title{
Tangshen formula attenuates hepatic steatosis by inhibiting hepatic lipogenesis and augmenting fatty acid oxidation in $\mathrm{db} / \mathrm{db}$ mice
}

\author{
QIN KONG ${ }^{1,2}$, HAOJUN ZHANG ${ }^{2}$, TINGTING ZHAO ${ }^{2}$, WEIKU ZHANG ${ }^{2}$, \\ MEIHUA YAN $^{2}, \mathrm{XI} \mathrm{DONG}^{2}$ and PING LI ${ }^{1,2}$ \\ ${ }^{1}$ Graduate School of Peking Union Medical College, Chinese Academy of Medical Science and \\ Peking Union Medical College, Beijing; ${ }^{2}$ Beijing Key Laboratory for Immune-Mediated Inflammatory Diseases, \\ Institute of Clinical Medical Sciences, China-Japan Friendship Hospital, Beijing, P.R. China
}

Received February 1, 2016; Accepted November 3, 2016

DOI: 10.3892/ijmm.2016.2799

\begin{abstract}
Tangshen formula (TSF), a well-prescribed traditional Chinese formula, has been used in the treatment of diabetic nephropathy. However, whether TSF ameliorates dyslipidemia and liver injury associated with diabetes remains unclear. In this study, we examined the effects of TSF on lipid profiles and hepatic steatosis in $\mathrm{db} / \mathrm{db}$ mice. For this purpose, 8 -week-old $\mathrm{db} / \mathrm{db}$ mice were treated with TSF or saline for 12 weeks via gavage and $\mathrm{db} / \mathrm{m}$ mice were used as controls. Body weight and blood glucose levels were monitored weekly and bi-weekly, respectively. Blood samples were obtained for the analysis of lipids and enzymes related to hepatic function, and liver tissues were analyzed by histology, immunohistochemistry and molecular examination. The results revealed that TSF markedly reduced body weight, liver index [liver/body weight (LW/BW)] and improved lipid profiles, hepatic function and steatosis in $\mathrm{db} / \mathrm{db}$ mice. TSF induced the phosphoralation of AMP-activated protein kinase and inhibited the activity of sterol regulatory element-binding protein 1 together with the inhibition of the expression of genes involved in de novo lipogenesis (DNL) and gluconeogenesis, such as fatty acid synthase (FAS), acetyl-CoA carboxylase (ACC), stearoyl CoA desaturase 1 (SCD1), glucose-6-phosphatase (G6pc) and phosphoenolpyruvate carboxykinase 1 (Pck1). Additionally, the silent mating type information regulation 2 homolog 1 (Sirt1)/ peroxisome proliferator-activated receptor $\alpha(\operatorname{PPAR} \alpha) /$ malonylCoA decarboxylase (MLYCD) cascade was potently activated by TSF in the liver and skeletal muscle of $\mathrm{db} / \mathrm{db}$ mice, which led to enhanced fatty acid oxidation. These findings demonstrated that TSF attenuated hepatic fat accumulation and steatosis in
\end{abstract}

Correspondence to: Dr Ping Li, Beijing Key Laboratory for ImmuneMediated Inflammatory Diseases, Institute of Clinical Medical Sciences, China-Japan Friendship Hospital, 2 Yinghua Donglu, Hepingli, Chaoyang, Beijing 100029, P.R. China

E-mail:1p8675@163.com

Key words: Tangshen formula, hepatic steatosis, lipogenesis, fatty acid oxidation $\mathrm{db} / \mathrm{db}$ mice by inhibiting lipogenesis and augmenting fatty acid oxidation.

\section{Introduction}

Type 2 diabetes has become one of the most rapidly escalating epidemics and debilitating chronic disease, which is a major public health challenge. Importantly, over $80 \%$ of the individuals diagnosed with type 2 diabetes are obese (1). A major metabolic consequence of diabetes and obesity is the abnormal deposition of triglycerides in hepatocytes (hepatic steatosis) and liver injury, which results in non-alcoholic fatty liver disease (NAFLD). In addition, diabetes and obesity are comorbid diseases associated with the dysfunction of lipid metabolism. Moreover, the prevalence of NAFLD in individuals with diabetes, obesity and dyslipidaemia is higher (35-80\%) than that in individuals without these conditions (2).

Abnormal lipid accumulation in hepatocytes leading to hepatic steatosis is due to two major metabolic perturbations: augmented hepatic de novo lipogenesis (DNL) and reduced fat combustion. DNL is an essential mechanism for lipid accumulation in the liver, which is often closely associated with the inhibition of AMP-activated protein kinase (AMPK) (3). AMPK, a key energy sensor and regulator of whole-body metabolism, has been demonstrated to be tightly involved in the development and disease processes of obesity and related metabolic disorders (4-6). Moreover, one critical lipogenic transcription factor is sterol regulatory element-binding protein 1 (SREBP1), which is primarily responsible for DNL by regulating genes involved in fatty acid and triglyceride synthesis, including fatty acid synthase (FAS), acetyl coenzyme A carboxylase [acetyl-CoA carboxylase (ACC)], and stearoyl CoA desaturase 1 (SCD1) $(7,8)$. Studies have shown that silent mating type information regulation 2 homolog 1 (Sirt1) plays a central role in modulating hepatic fatty acid metabolism through AMPK and SREBP1, that is a critical mediator of fatty acid combustion and synthesis $(9,10)$.

Although considerable progress has been made in understanding the molecular mechanisms involved in NAFLD, satisfactory treatment options for this disease remain limited (11). Tangshen formula (TSF), a Chinese herbal formula, 
has been shown to be capable of treating diabetic nephropathy, a serious complication of diabetes $(12,13)$. However, whether TSF ameliorates liver injury in diabetes conditions is unclear. $\mathrm{C} 57 \mathrm{BL} / \mathrm{KsJ}-\mathrm{db} / \mathrm{db}$ mice, which have a mutation in the leptin receptor gene, develop obesity, hyperglycemia, hyperlipidemia and hepatic steatosis and also develop type 2 diabetes; thus, these animals constitute a useful animal model for the study of NAFLD (14). In this study, we aimed to determined whether TSF attenuates hepatic steatosis, and also iamed to elucidate the underlying mechanisms using $\mathrm{db} / \mathrm{db}$ mice. Our findings reveal novel metabolic activities of TSF in the liver, which point to the potential use of TSF in the treatment of NAFLD.

\section{Materials and methods}

Herbal materials and the preparation of TSF. TSF granules were composed of the following herbs: Astragalus membranaceus (Fisch.) Bge. (Leguminosae, voucher specimen no. 412303), Euonymus alatus (Thunb.) Siebold (Celastraceae, voucher specimen no. 1412301), Rehmannia glutinosa Libosch. (Scrophulariaceae, voucher specimen no. 1411616), Citrus aurantium L. (Rutaceae, voucher specimen no. 1412304), Cornus officinalis Sieb. et Zuce (Cornaceae, voucher specimen no. 1410652), Rheum palmatum L. (Polygonaceae, voucher specimen no. 1412302), and Panax notoginseng (Burk.) F.H. Chen (Araliaceae, voucher specimen no. 1410004) in the ratio of 10:5:4:3.4:3:2:1 (W/W). The herbs were prepared and standardized by Jiangyin Tianjiang Pharmaceutical (Jiangyin, Jiangsu, China). The percentage of powered herb was determined as follows: the herbal drugs were authenticated and standardized on marker compounds according to the Chinese Pharmacopoeia (2010 edition). Each gram of each granule was equivalent to $12.75 \mathrm{~g}$ of the raw herbs. The granules were dissolved in distilled water $(0.18 \mathrm{~g} / \mathrm{ml})$ for experimental use.

Chromatographic analysis of TSF. TSF was dissolved in distilled water and filtered through a $0.45 \mu \mathrm{m}$ filtration membrane prior to being subjected to high performance liquid chromatography (HPLC) analyses. HPLC analyses were carried out using an Agilent HPLC system (Agilent Technologies, Santa Clara, CA, USA). Chromatographic analysis was performed on an Agilent 1100 system using a Phenomenex Luna $\mathrm{C}_{18}$ column $(4.6 \times 250 \mathrm{~mm}, 5 \mu \mathrm{m}$; Torrance, CA, USA). Oven temperature was maintained at $30^{\circ} \mathrm{C}$. Methanol (A) and water containing $0.1 \%$ acetic acid (B) served as the mobile phase. The gradient elution program was as follows: 0-60 min, a linear gradient from 5 to $100 \%$ (A). The low rate was $1.0 \mathrm{ml} / \mathrm{min}$ and the detection wavelength was set at $254 \mathrm{~nm}$. Pure standards that were used as external standards during HPLC analysis (Fig. 1) included loganin (voucher specimen no. 111640-201005), calycosin-7-O- $\beta$-D-glucoside (voucher specimen no. 111920-201203), naringenine-7-rhamnosidoglucoside (voucher specimen no. STA-02106005), neohesperidin (voucher specimen no. 111857-201102), naringenin (voucher specimen no. STA-02206006) and Aloe-emodin (voucher specimen no. 110795-201007) and were purchased from the National Institutes for Food and Drug Control (Beijing, China) and Shanghai Nature Standard R\&D and Biotech (Shanghai, China).
Animals. The study protocol was approved by the Ethics Committee of the China-Japan Friendship Institute of Clinical Medical Sciences (Approval no. 13005) and all experiments were performed in accordance with the NIH Guiding Principles for the Care and Use of Laboratory Animals. Eight-week-old male C57BLKS/J db/db and $\mathrm{db} / \mathrm{m}$ mice (Peking University Laboratory Animal Center, Beijing, China) were housed at $23 \pm 3^{\circ} \mathrm{C}$ and humidity of $55 \pm 15 \%$ on a 12 -h light-dark cycle and were allowed access to standard chow and water ad libitum. After 2 weeks of feeding adaptation, the $\mathrm{db} / \mathrm{db}$ mice were divided into 2 groups (at 10 weeks of age) as follows: one that received TSF via intra-gastric gavage $(\mathrm{n}=9 ; \mathrm{db} / \mathrm{db}+\mathrm{TSF}, 2.4 \mathrm{~g} / \mathrm{kg} / \mathrm{day})$, another pair-fed group that received saline instead of TSF $(n=9 ; \mathrm{db} / \mathrm{db})$. The $\mathrm{db} / \mathrm{m}$ mice were used as controls $(\mathrm{n}=9, \mathrm{db} / \mathrm{m})$. The TSF dosage was based on our previous study and standard conversion formula (body surface areas) $(15,16)$. Body weight was measured weekly (g). The reducing effects of TSF on body weight are presented as the $95 \%$ confidence level $(95 \% \mathrm{CI})$ and the top limit/bottom limit of $95 \% \mathrm{CI}=$ mean \pm SE x Tinv $(0.05, \mathrm{n}-1)$. The mice were maintained on TSF treatment for 12 weeks and were then sacrificed under anesthesia. Animal blood was collected via the tail vein and the eye socket for further analysis. Liver and skeletal muscles (the rear part of the left leg) were also collected.

Measurement of serum parameters. All blood samples were collected after overnight fasting. Serum alanine aminotransferase (ALT), aspartate transaminase (AST), albumin (ALB), triglycerides and total cholesterol, low-density lipid cholesterol (LDL-C), high-density lipid cholesterol (HDL-C) and fasting blood glucose (FBG) levels were measured using an automatic analyzer (Abbott Diagnostics, Abbott Park, IL, USA). Fasting blood glucose (FBG) was measured bi-weekly. Serum free fatty acid (FFA) levels were determined by enzymatic methods (Meilian Biological, Shanghai, China) according to the manufacturer's instructions. All measurements were performed in a blinded manner.

Liver histological and immunohistochemical analyses. The liver tissues were removed and weighed to determine the liver index [liver/body weight (LW/BW)]. Liver samples were fixed in $10 \%$ neutral-buffered formalin, embedded in paraffin, and sectioned into 5- $\mu \mathrm{m}$-thick slices on slides. Hematoxylin and eosin (H\&E; Beyotime, Jiangsu, China) staining was performed using standard protocols and scored blindly for the degree of fatty liver on a scale 0-3, as previously described (17). For Oil Red O staining, cryosections of the liver (5- $\mu \mathrm{m}$-thick) were air-dried for $10 \mathrm{~min}$ at room temperature, washed with $60 \%$ isopropanol and stained with fresh Oil Red O working solution (Sigma-Aldrich, St. Louis, MO, USA). After washing with $60 \%$ isopropanol, the sections were placed under a microscope (Olympus, Tokyo, Japan) to visualize lipid deposition. All samples were analyzed blindly for overall pathology using Image-Pro Plus software (Media Cybernetics, Warrendale, PA, USA). Immunohistochemistry and periodic-acid Schiff (PAS) staining of liver glycogen was performed as previously described (18). Briefly, the livers were fixed in $10 \%$ formalin and embedded in paraffin wax. Paraffin sections were cut and mounted on slides. After microwave-based heating antigen retrieval, the sections were stained with antibodies at $4^{\circ} \mathrm{C}$ overnight, followed by horseradish peroxidase-conjugated second antibodies (Gene Tech, Shanghai, China) at room tempera- 


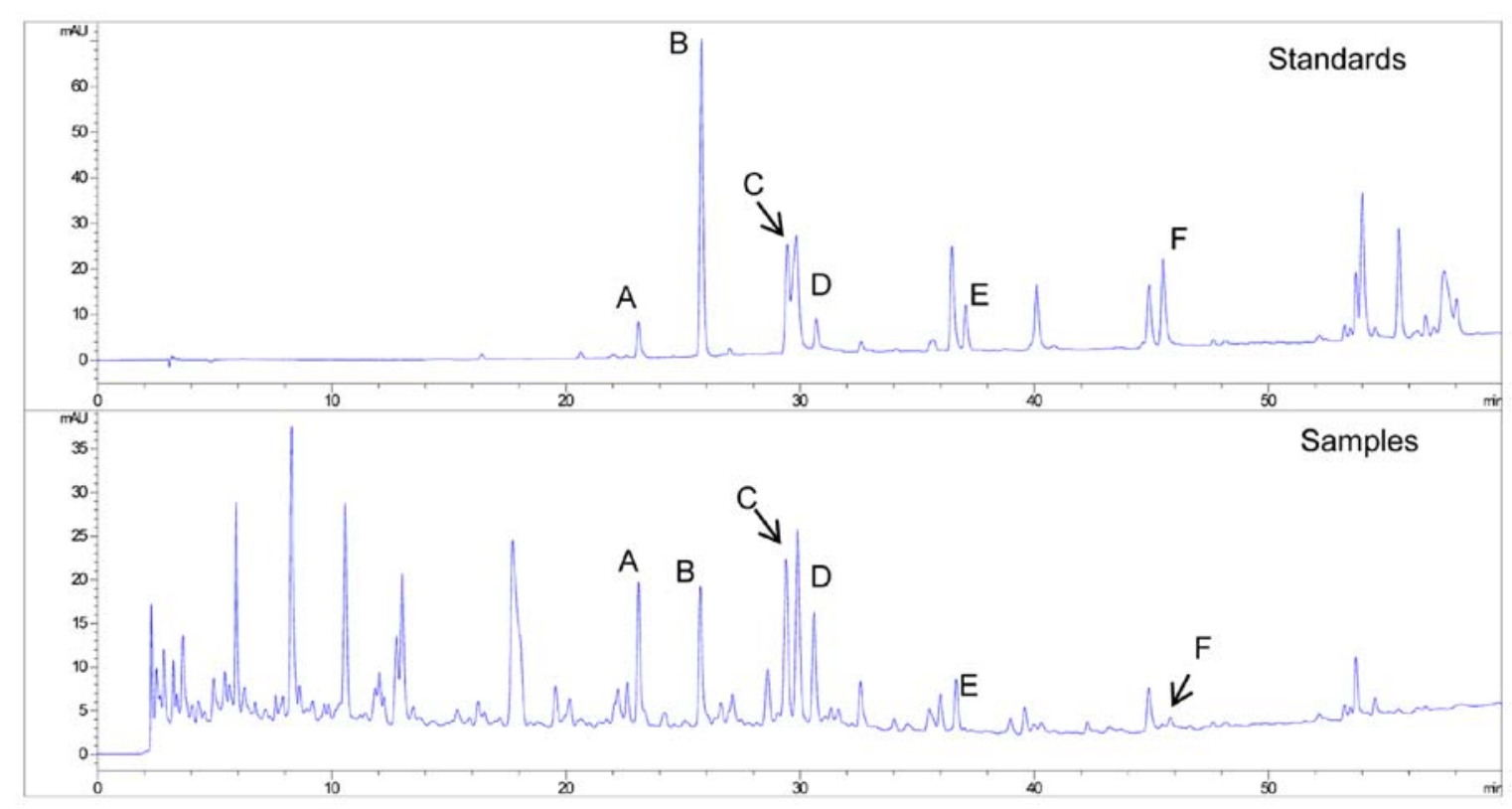

Figure 1. High performance liquid chromatography (HPLC) chromatogram of Tangshen formula (TSF). TSF was subjected to HPLC analysis, and its chemical fingerprint was revealed by a DAD detector. (A) Loganin, (B) calycosin-7-O- $\beta$-D-glucoside, (C) naringenine-7-rhamnosidoglucoside, (D) neohesperidin, (E) naringenin, (F) aloe-emodin were identified in the HPLC fingerprint at $254 \mathrm{~nm}$. Chemical structures are depicted in Fig. 8.

ture for $1 \mathrm{~h}$ and captured using a light microscope (Olympus). For PAS staining, the sections were stained with periodic-acid Schiff (Beyotime) for $15 \mathrm{~min}$ and hematoxylin for $1 \mathrm{~min}$.

Immunofluorescence staining and confocal microscopy. Immunofluorescence staining of the liver tissues was performed under cryoprotection as previously described with minor modifications (19). The mouse livers were excised, fixed in $4 \%$ paraformaldehyde and $30 \%$ sucrose solution, and processed for embedding with optimal cutting temperature compound (Sakura Finetek, Tokyo, Japan). Cryosectioning was performed at $-20^{\circ} \mathrm{C}$, and the frozen liver tissues were sectioned into $5-\mu \mathrm{m}$-thick slices followed by mounting on glass slides. For immunofluorescence staining, the sections were air-dried on a bench for $10 \mathrm{~min}$, and were blocked in phosphate-buffered saline (PBS) containing $0.1 \% \mathrm{BSA}$ and incubated overnight at $4^{\circ} \mathrm{C}$ with an anti-SREBP1 antibody (ab28481; Abcam, Cambridge, MA, USA) at a dilution of 1/200 followed by incubation with Alexa-conjugated goat anti-rabbit secondary antibody (\#CA11008s; Invitrogen, Carlsbad, CA, USA) for $1 \mathrm{~h}$. Following 3 rinses with PBS, the sections were mounted with PBS with $5 \mu \mathrm{g} / \mathrm{ml}$ of 4',6-damidino2-phenylindole dihydrochloride (DAPI; Sigma-Aldrich) and the specimens were imaged under a Leica DM6000 CS confocal microscope (Leica Microsystems, Wetzlar, Germany).

Reverse transcription-quantitative polymerase chain reaction $(R T-q P C R)$. Total RNA prepared from the mouse tissues was extracted using TRIzol reagent (Invitrogen) according to the manufacture's instructions. The RNA concentration of all samples was quantified using a NanoDrop-1000 spectrophotometer (NanoDrop Technologies, Wilmington, DE, USA). Total RNA was reverse transcribed using the Total RevertAid First Strand cDNA synthesis kit (Thermo Scientific, Waltham, MA, USA) and quantitative PCR (qPCR) was performed using UltraSYBR Mixture (CWBio, Beijing, China). The results were normalized to $\beta$-actin expression using the $\Delta \Delta \mathrm{C}(\mathrm{t})$ threshold cycle method, as previously described (20). The specific primer sequences are listed in Table I.

Western blot analysis. The mouse tissues were homogenized in RIPA lysis buffer supplemented with protease and phosphatase inhibitors cocktail (Roche Diagnostics, Mannheim, Germany). The protein concentration was measured using a Bicinchoninic acid assay (BCA) method (Beijing Solarbio Science and Technology, Beijing, China). Lysates of 25-50 $\mu \mathrm{g}$ protein were separated by $8-12 \%$ sodium dodecyl sulfate (SDS) gel and transferred onto polyvinylidene fluoride (PVDF) membranes (Millipore, Billerica, MA, USA). The membranes were then blocked with 5\% BSA in Tris-buffered saline and Tween-20 (TBST) followed by incubation with primary and secondary antibodies. The primary antibodies used were against the following proteins: AMPK (\#2532), phosphorylated (p-)AMPK (\#2535), ACC (\#3676), p-ACC (\#3661), p-Akt (\#4060), Akt (\#4691), phosphoinositide 3-kinase (PI3K; \#4257), p-mammalian target of rapamycin (p-mTOR; \#2971), mTOR (\#2983), Sirt1 (\#2028), and SCD1 (\#2794) (all from Cell Signaling Technology, Danvers, MA, USA), SREBP1 (sc8984), peroxisome proliferator-activated receptor (PPAR) $\alpha$ (sc9000), $\beta$-actin (sc69879) (Santa Cruz Biotechnology, Inc., Santa Cruz, CA, USA), 3'-hydroxylmethyl glutaryl coenzyme A reductase (HMGCR; ab174830), liver X receptor $\alpha$ (LXR $\alpha$; ab176323), malonyl-CoA decarboxylase (MLYCD; ab95945), carnitine palmitoyltransferase 1 (CPT1A; ab128568), PPAR $\gamma$ coactivator $1 \alpha$ (PGC1 $\alpha$; ab54481) (all from Abcam). The anti-mouse (\#115-035-003) or anti-rabbit (\#111-035-003) secondary antibodies were from Jackson ImmunoResearch, West Grove, PA, USA. Signals were visualized on a ChemiDoc XRS system (BioRad, Hercules, CA, USA) and the protein bands were quantified by densitometry using the ImageJ program (National Institutes of Health, Bethesda, MD, USA). 
Table I. List of primers used for RT-qPCR.

\begin{tabular}{lllr}
\hline Gene & \multicolumn{1}{c}{ Forward primer } & \multicolumn{1}{c}{ Reverse primer } & PCR size (bp) \\
\hline SREBP1 & GGAGCCATGGATTGCACATT & GGCCCGGGAAGTCACTGT & 70 \\
HMGCR & CTTGTGGAATGCCTTGTGATTG & AGCCGAAGCAGCACATGAT & 76 \\
Acc1 & AATGAACGTGCAATCCGATTTG & ACTCCACATTTGCGTAATTGTTG & 136 \\
FAS & GCTGCGGAAACTTCAGGAAAT & AGAGACGTGTCACTCCTGGACTT & 84 \\
SCD1 & TTCTTCTCTCACGTGGGTTG & CGGGCTTGTAGTACCTCCTC & 130 \\
Acadm & AGGGTTTAGTTTGAGTTGACGG & CCCCGCTTTTGTCATATTCCG & 110 \\
PGC1 $\alpha$ & TATGGAGTGACATAGAGTGTGCT & CCACTTCAATCCACCCAGAAAG & 134 \\
PPAR $\alpha$ & AACATCGAGTGTCGAATATGTGG & CCGAATAGTTCGCCGAAAGAA & 99 \\
Cpt1A & CTCCGCCTGAGCCATGAAG & CACCAGTGATGATGCCATTCT & 100 \\
Cpt1B & GCACACCAGGCAGTAGCTTT & CAGGAGTTGATTCCAGACAGGTA & 107 \\
Acox1 & CCGCCACCTTCAATCCAGAG & CAAGTTCTCGATTTCTCGACGG & 86 \\
Pck1 & CTGCATAACGGTCTGGACTTC & GCCTTCCACGAACTTCCTCAC & 87 \\
G6pc & CGACTCGCTATCTCCAAGTGA & GTTGAACCAGTCTCCGACCA & 173 \\
LXR $\alpha$ & ATGTCTTCCCCCACAAGTTCT & GACCACGATGTAGGCAGAGC & 156 \\
Esrra & CTCAGCTCTCTACCCAAACGC & CCGCTTGGTGATCTCACACTC & 168 \\
Tfam & ATTCCGAAGTGTTTTCCAGCA & TCTGAAAGTTTGCATCTGGGT & 122 \\
LPL & GGGAGTTTGGCTCCAGAGTTT & TGTGTCTTCAGGGGTCCTTAG & 115 \\
FAT/CD36 & AGATGACGTGGCAAAGAACAG & CCTTGGCTAGATAACGAACTCTG & 83 \\
\hline
\end{tabular}

Table II. Blood parameters of the mice in the study groups ${ }^{\mathrm{a}}$.

\begin{tabular}{lccc}
\hline & $\mathrm{db} / \mathrm{m}$ & $\mathrm{db} / \mathrm{db}$ & $\mathrm{db} / \mathrm{db}+\mathrm{TSF}$ \\
\hline ALT (U/l) & $52.00 \pm 4.12$ & $192.00 \pm 23.87^{\mathrm{b}}$ & $96.57 \pm 9.78^{\mathrm{c}}$ \\
AST (U/l) & $143.6 \pm 4.18$ & $216.2 \pm 19.52^{\mathrm{b}}$ & $149.4 \pm 5.83^{\mathrm{c}}$ \\
ALB (g/l) & $42.60 \pm 0.95$ & $42.80 \pm 1.36$ & $42.73 \pm 1.17$ \\
Cholesterol & $2.60 \pm 0.13$ & $4.19 \pm 0.11^{\mathrm{b}}$ & $3.20 \pm 0.17^{\mathrm{c}}$ \\
(mmol/l) & & & \\
Triglyceride & $0.65 \pm 0.03$ & $1.05 \pm 0.05^{\mathrm{b}}$ & $0.93 \pm 0.01^{\mathrm{c}}$ \\
(mmol/l) & & & \\
HDL-C (mmol/l) & $2.49 \pm 0.16$ & $3.43 \pm 0.10^{\mathrm{b}}$ & $3.42 \pm 0.11$ \\
LDL-C (mmol/l) & $0.80 \pm 0.05$ & $1.39 \pm 0.04^{\mathrm{b}}$ & $1.05 \pm 0.03^{\mathrm{c}}$ \\
FFA (mmol/l) & $0.74 \pm 0.03$ & $1.07 \pm 0.05^{\mathrm{b}}$ & $0.89 \pm 0.03^{\mathrm{c}}$ \\
\hline
\end{tabular}

${ }^{\mathrm{a}}$ Data shown are the means $\pm \mathrm{SEM} ;{ }^{\mathrm{b}} \mathrm{P}<0.05 \mathrm{vs} . \mathrm{db} / \mathrm{m} ;{ }^{\mathrm{c}} \mathrm{P}<0.05 \mathrm{vs} . \mathrm{db} / \mathrm{db}$. ALB, albumin; ALT, aminotransferase; AST, aspartate transaminase; HDL-C, high-density lipid cholesterol; LDL-C, low-density lipid cholesterol; FFA, free fatty acid.

Statistical analysis. The results are presented as the mean values \pm SEM. Statistical analyses were performed using GraphPad Prism software version 6.0 (GraphPad Software, La Jolla, CA, USA) by analysis of one-way variance (ANOVA). Differences were considered significant at $\mathrm{P}<0.05$.

\section{Results}

Treatment with TSF diminishes weight gain and resolves hepatic steatosis in $\mathrm{db} / \mathrm{db}$ mice. During the experimental period, the $\mathrm{db} / \mathrm{db}$ mice exhibited a markedly higher body weight and FBG levels. Treatment with TSF diminished the increase in body weight, but not in FBG levels (Fig. 2A and D).
An inhibitory effect of TSF on weight gain in $\mathrm{db} / \mathrm{db}$ mice was observed and this reached statistical significant as early as the 16th week (Fig. 2A). There was a 19.36\% (95\% CI, 33.67-5.05\%) reduction in weight gain in the $\mathrm{db} / \mathrm{db}$ mice treated with TSF at 22 weeks. The increase in liver weight and the liver index of the $\mathrm{db} / \mathrm{db}$ mice was reduced in the mice treated with TSF at the time of sacrifice (Fig. 2B and C). The serum enzyme, triglycerides, total cholesterol, LDL-C and FFA levels were also significantly increased in the $\mathrm{db} / \mathrm{db}$ mice as compared with the $\mathrm{db} / \mathrm{m}$ mice, and these effects were inhibited by TSF. However, HDL-C was modestly increased in the $\mathrm{db} / \mathrm{db}$ mice, but was not restored by treatment with TSF (Table II).

In consonance with the biochemical data, the $\mathrm{db} / \mathrm{db}$ mice that received TSF exhibited a significant reduction in histological steatosis. The histopathological evaluation of formalin-fixed, H\&E stained liver slides revealed clear vesicular steatosis in the livers of the $\mathrm{db} / \mathrm{db}$ mice compared with those of the TSF-treated mice (Fig. 2E). Oil Red O staining performed on the cryosections of liver tissues demonstrated that treatment with TSF alleviated the accumulation of triglycerides (Fig. 2E).

TSF inhibits the expression of hepatic lipogenic enzymes in the livers of $d b / d b$ mice and these effects are mediated by AMPK/ SREBPI. FAS, ACC and SCD1, the key targets of SREBP1, are key enzymes regulating cellular lipogenesis and lipid homeostasis (21). The results of western blot analysis and RT-qPCR indicated that the administration TSF markedly decreased the protein and mRNA levels of FAS and SCD1 (enzymes involved in fatty acid and triglyceride synthesis) in the livers of $\mathrm{db} /$ $\mathrm{db}$ mice (Fig. 3A and C). Similarly, the levels of the key enzyme of cholesterol biosynthesis, HMGCR, was prominently inhibited by TSF in the livers of db/db mice (Fig. 3A and C). Moreover, the decreased protein expression of FAS and HMGCR, the two essential lipogenic enzymes, was further confirmed by immunohistochemical analysis of the hepatic sections (Fig. 3B). In 
A

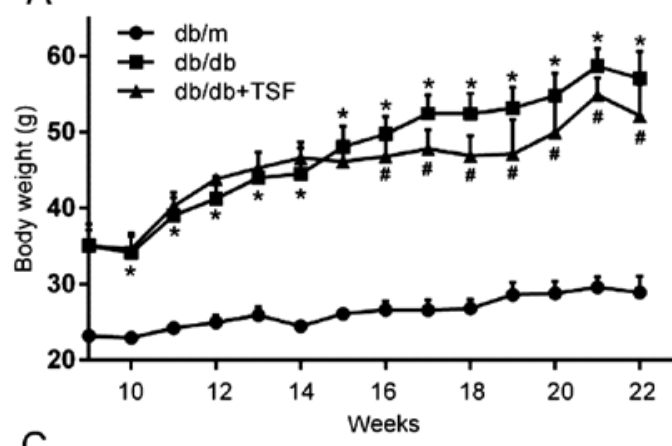

C

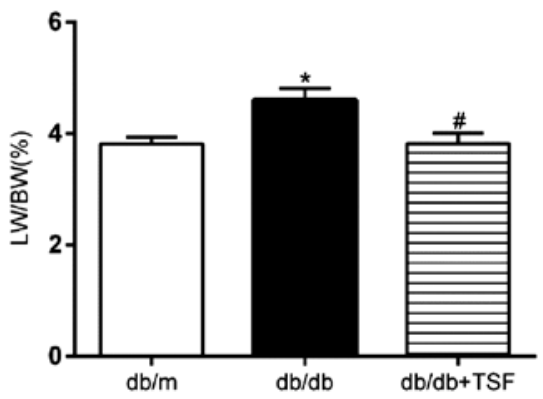

B
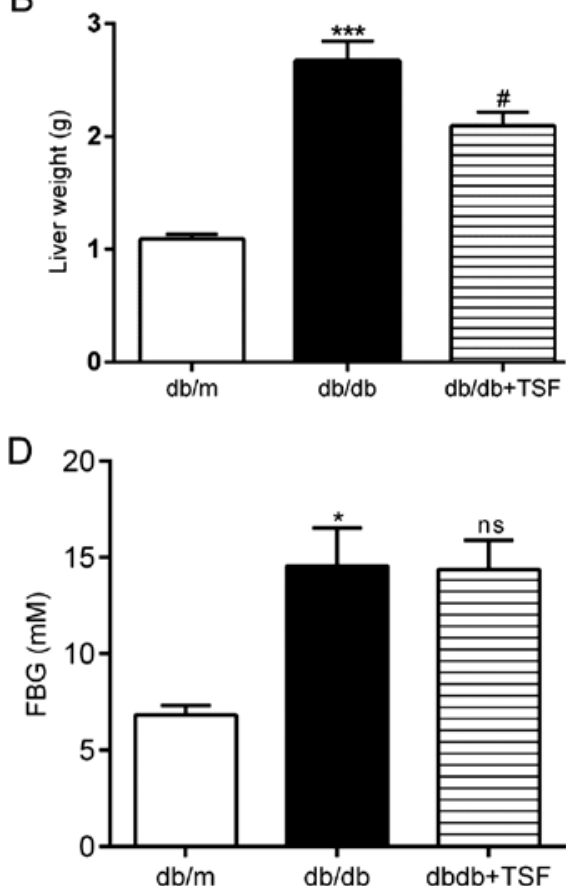

E

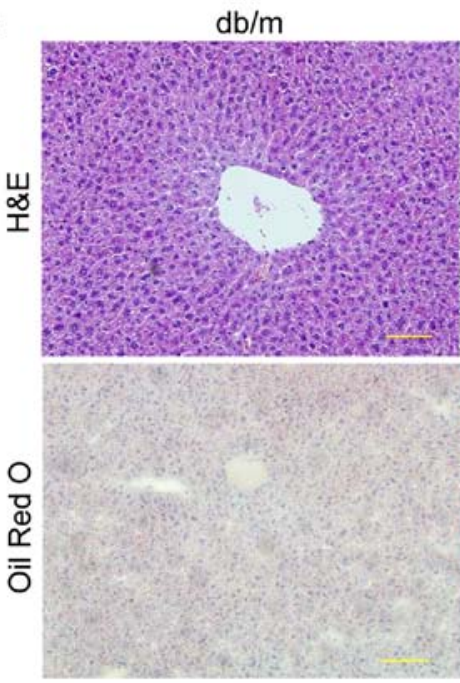

$d b / d b$

$\mathrm{db} / \mathrm{db}+\mathrm{TSF}$
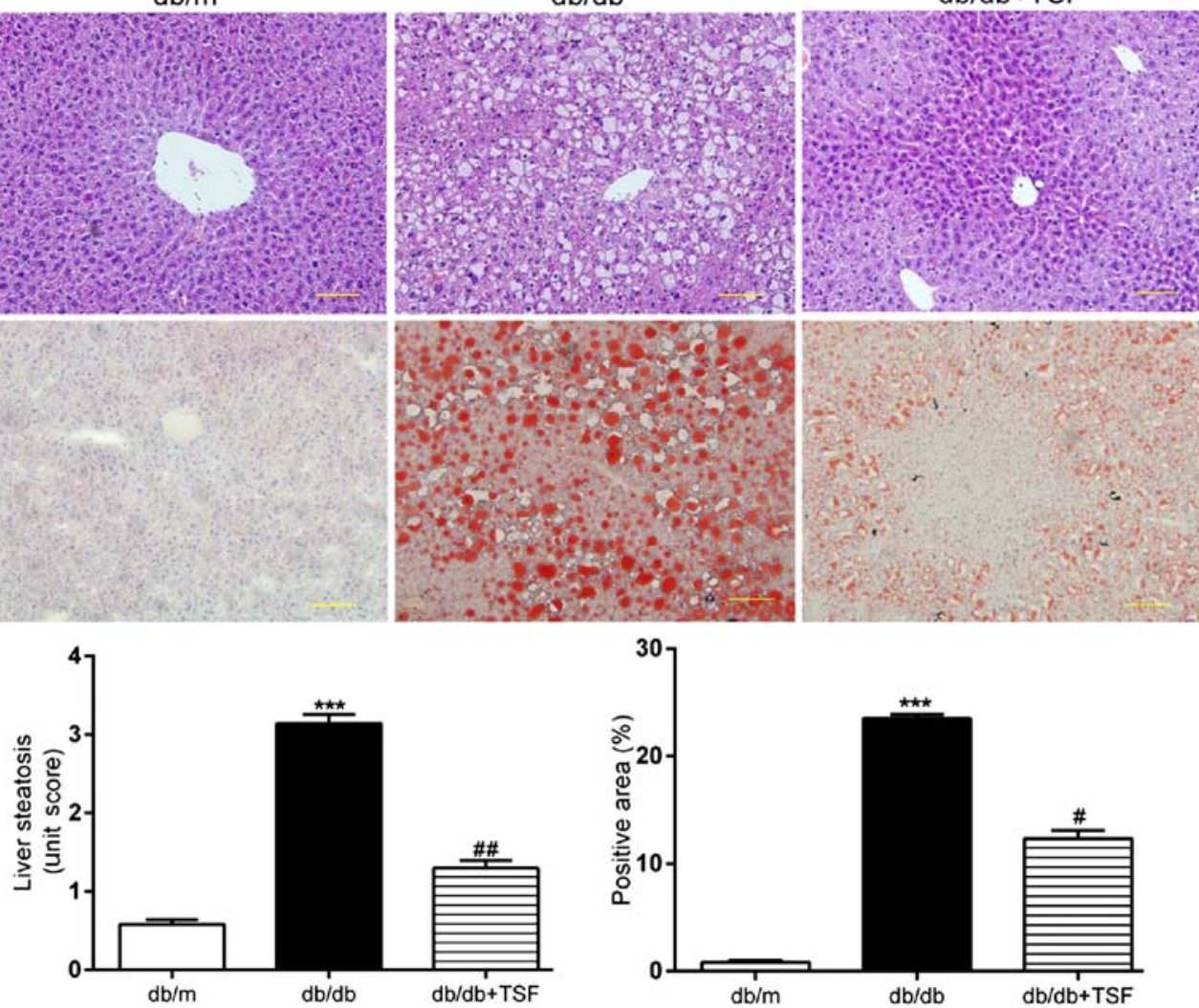

Figure 2. Treatment with Tangshen formula (TSF) suppresses weight gain and reduces lipid accumulation in the livers of db/db mice. (A) The administration of TSF for 12 weeks effectively diminished body weight gain in $\mathrm{db} / \mathrm{db}$ mice. An inhibitory trend was detected and reached statistical significance as early as week 6 of TSF treatment. (B and C) Treatment with TSF decreased liver weight and liver weight/body weight (LW/BW). (D) Fasting blood glucose (FBG) for each group. (E) Representative H\&E and Oil Red O staining revealed markedly diminished vesicular steatosis and fat accumulation in the livers of TSF-treated mice. Scale bar, $100 \mu \mathrm{m}$. Data are presented as the means \pm SEM. ${ }^{*} \mathrm{P}<0.05$ and ${ }^{* * *} \mathrm{P}<0.001 \mathrm{vs}$. db/m group; ${ }^{\#} \mathrm{P}<0.05$ and ${ }^{\# \#} \mathrm{P}<0.01 \mathrm{vs}$. db/db group; ns, no significance.

addition, the mRNA level and protein expression of $\mathrm{p}-\mathrm{ACC}$, an AMPK downstream target, was decreased in the $\mathrm{db} / \mathrm{db}$ mice its levels were and restored by treatment with TSF (Fig. 3A).
It has been shown that the Thr172 phosphorylation of AMPK (p-AMPK) blunts the cleavage of the protein of SREBP1 and inhibits its nuclear translocation, which results in the amelio- 

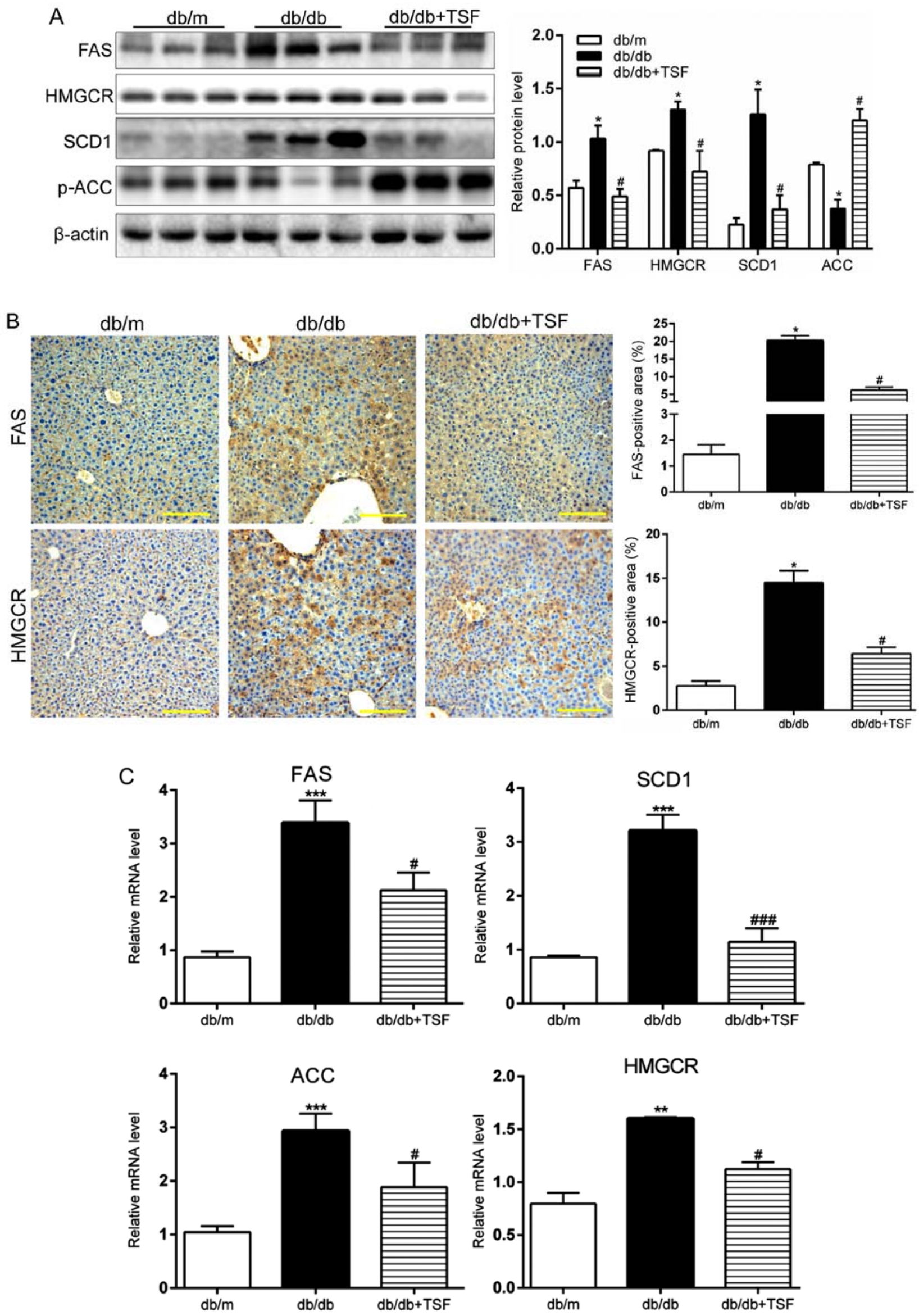

Figure 3. Tangshen formula (TSF) inhibits the expression of hepatic lipogenic enzymes in the $\mathrm{db} / \mathrm{db}$ mice. (A and C) Protein and mRNA (relative fold change) levels of lipogenic genes in the livers of db/db mice. (B) Representative images of hepatic sections stained for lipogenic enzymes fatty acid synthase (FAS), 3'-hydroxylmethyl glutaryl coenzyme A reductase (HMGCR) (left panel) and semi-quantitative analysis (right panel). Scale bar, $100 \mu \mathrm{m}$. Data are presented as the means \pm SEM. ${ }^{*} \mathrm{P}<0.05,{ }^{* *} \mathrm{P}<0.01$ and ${ }^{* * * *} \mathrm{P}<0.001$ vs. $\mathrm{db} / \mathrm{m}$ group; ${ }^{\#} \mathrm{P}<0.05$, and ${ }^{\# \# \# "} \mathrm{P}<0.001 \mathrm{vs}$. $\mathrm{db} / \mathrm{db}$ group. 

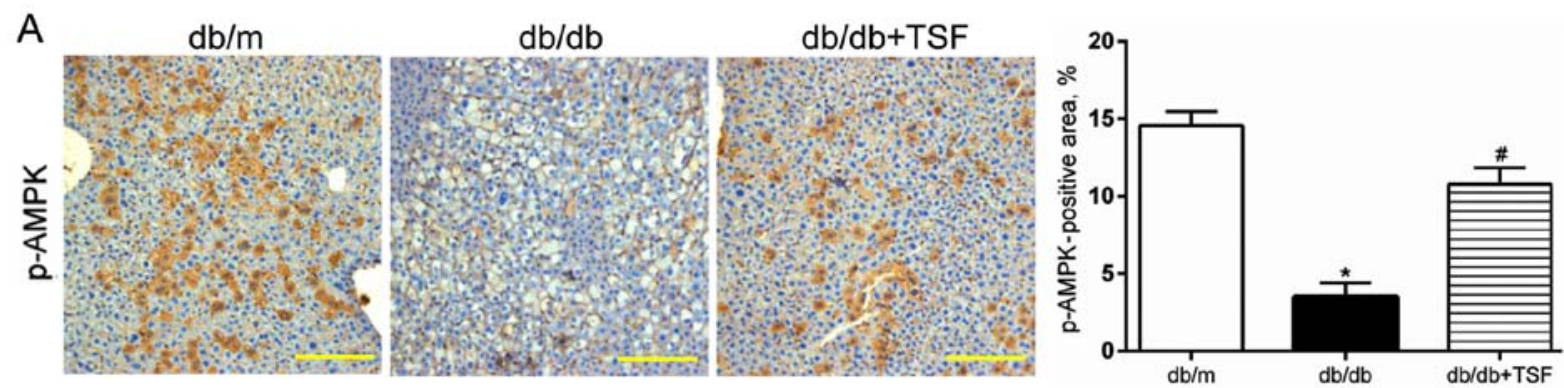

B
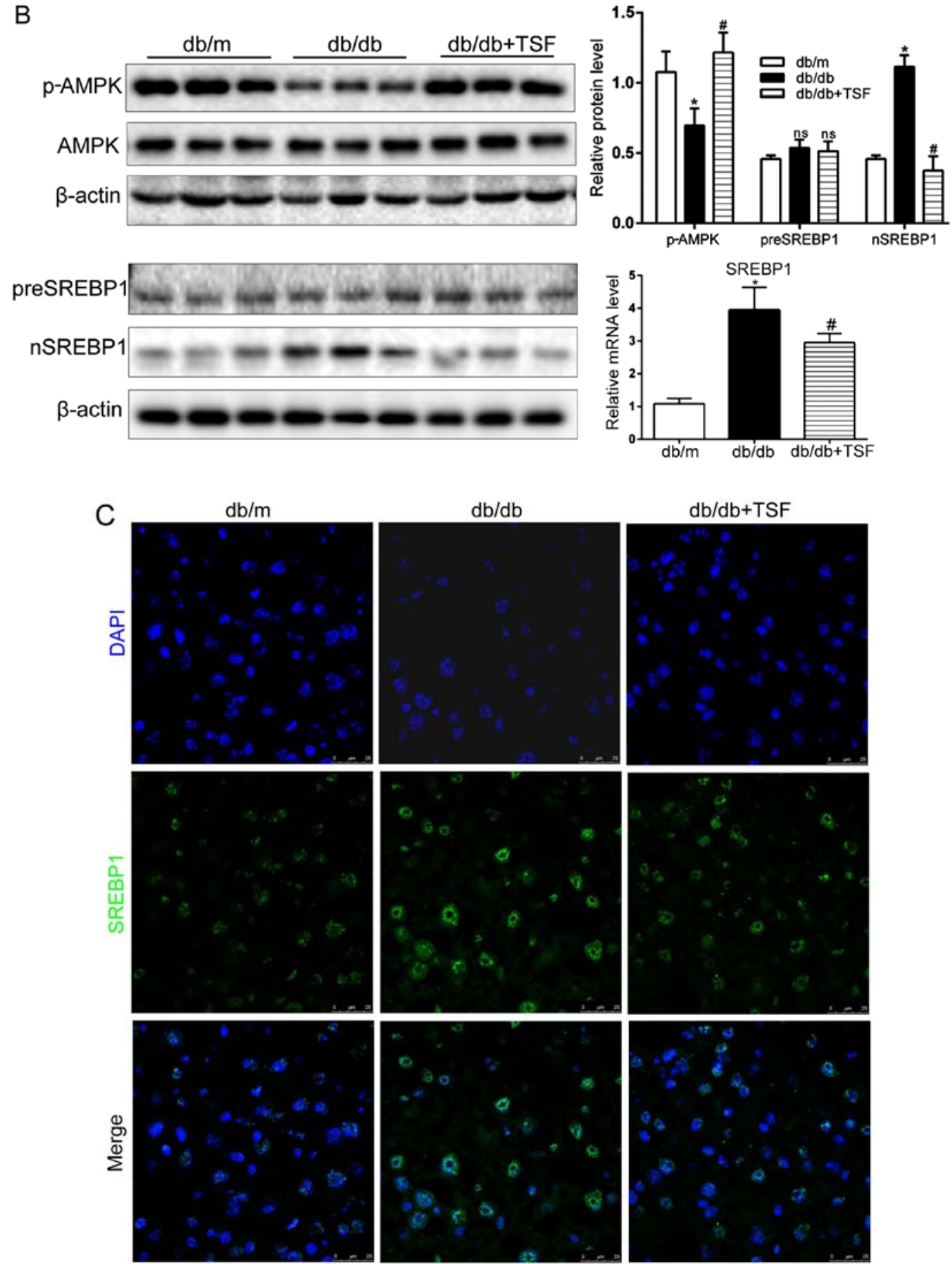

Figure 4. Tangshen formula (TSF) activates the phosphorylation of AMPK and attenuates the nuclear translocation of sterol regulatory element-binding protein 1 (SREBP1) in the livers of db/db mice. (A) Representative photomicrographs of p-AMPK staining and semi-quantitative analysis. Scale bar, $100 \mu$ m. (B) Western blot analysis assessed the protein levels of total and thephosphorylation of AMPK, precursor forms of hepatic SREBP1 (preSREBP1), and nuclear form (nSREBP1). The SREBP1 mRNA level was quantified by RT-qPCR. (C) Representative images of immunofluorescence staining for SREBP1 (green) and nucleus (blue) was photographed by confocal microscopy. Scale bar, $25 \mu \mathrm{m}$. ns, not significant. Data are presented as the means $\pm \mathrm{SEM}$. ${ }^{*} \mathrm{P}<0.05 \mathrm{vs}$. db/m group; ${ }^{\#} \mathrm{P}<0.05$ vs. $\mathrm{db} / \mathrm{db}$ group. 

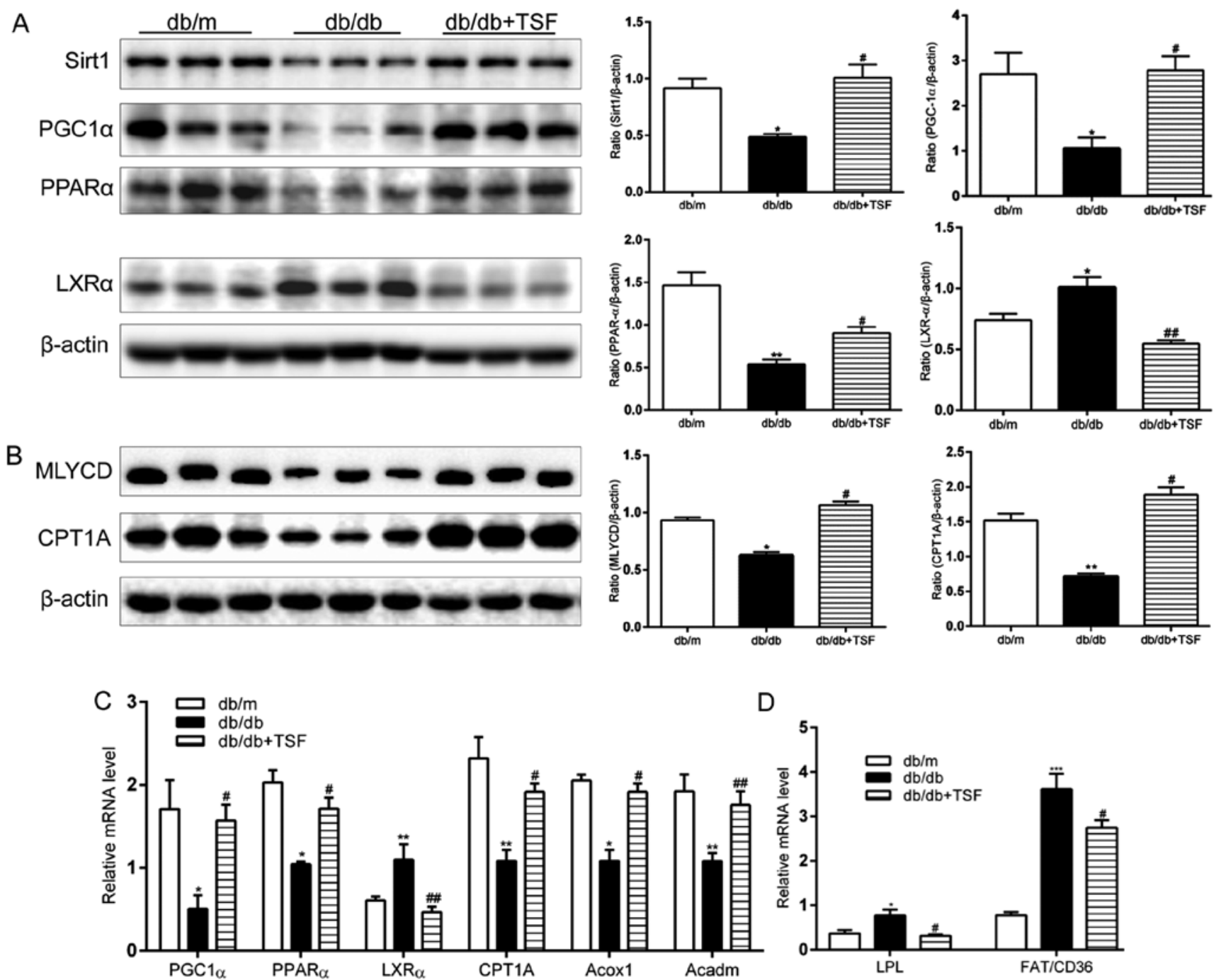

Figure 5. Tangshen formula (TSF) promotes silent mating type information regulation 2 homolog 1 (Sirt1) upregulation and activates the Sirt1/peroxisome proliferator-activated receptor (PPAR $\alpha$ )/malonyl-CoA decarboxylase (MLYCD) signaling pathway. (A and B) Western blot analyses assessed the abundance of Sirt1, PGC1 $\alpha$, PPAR $\alpha, \mathrm{LXR} \alpha$, carnitine palmitoyltransferase 1A (CPT1A) and MLYCD in the liver. (C) Hepatic mRNA levels (expressed as fold change) of genes involved in fatty acid oxidation were quantified by RT-qPCR. (D) Hepatic mRNA expression of lipoprotein lipase (LPL) and fatty acid translocase CD36 (FAT/CD36). Data are presented as the means \pm SEM. ${ }^{*} \mathrm{P}<0.05$ and ${ }^{* * *} \mathrm{P}<0.01 \mathrm{vs}$. db/m group; ${ }^{*} \mathrm{P}<0.05$ and ${ }^{\# \prime \prime} \mathrm{P}<0.01$ vs. db/db group.

ration of hepatic steatosis $(22,23)$. In this study, we observed a decrease in the level of phosphorylation of AMPK in the livers of $\mathrm{db} / \mathrm{db}$ mice, and this was substantially restored by treatment with TSF (Fig. 4B). Moreover, the increased expression of p-AMPK induced by TSF was further confirmed by immunohistochemical analysis of the liver sections (Fig. 4A). We then examined the effect of TSF on SREBP1 activity, which is reflected by the amounts of cleavage and nuclear translocation. As shown in Fig. 4B and C, the accumulation of nuclear SREBP1 in the livers of $\mathrm{db} / \mathrm{db}$ mice was markedly reduced by TSF. The staining intensity of the nuclear active forms of SREBP1, in contrast, was largely reduced in the TSF-treated mice (Fig. 4C). The mRNA level of SREBP1 was further determined by RT-qPCR, and this was also shown to be significantly increased in the $\mathrm{db} / \mathrm{db}$ mice and was decreased by TSF (Fig. 4B). These data indicate that TSF attenuates hepatic steatosis, at least in part by the inhibition of SREBP1 and reducing its target gene transcription.

TSF regulates enzymes and genes involved in lipid combustion and mitochondrial biogenesis in the liver and skeletal muscle of $d b / d b$ mice. We then examined the metabolic genes involved in lipid combustion and found that TSF significantly increased the expression of Sirt1 in the livers of $\mathrm{db} / \mathrm{db}$ mice (Fig. 5A). Existing evidence indicates that hepatic Sirt1 regulates lipid homeostasis by positively regulating PPAR $\alpha$ (24). Therefore, we hypothesized that TSF exerts its 'anti-steatosis' effect in part by augmenting Sirt1-driven PPAR $\alpha$ upregulation in the fatty liver. We found that treatment with TSF increased the expression of PPAR $\alpha$, as well as that of PGC1 $\alpha$ in the livers of $\mathrm{db} / \mathrm{db}$ mice. Of note, we observed that the levels of LXR $\alpha$ were decreased by TSF treatment (Fig. 5A). which was consistent with the findings of previous studies; namely that the activation of LXR $\alpha$ induces the transcription of the lipogenic genes, SREBP1, FAS and ACC $(25,26)$.

Malonyl-CoA, the substrate of fatty acid synthesis, is also an inhibitor of CPT1, which regulates fatty acid oxidation (27). MLYCD, which generates acetyl-CoA from malonyl-CoA, has been shown to be activated by AMPK and PPAR $\alpha$ (28). In the present study, the administration of TSF clearly increased the MLYCD and CPT1A levels in the livers 

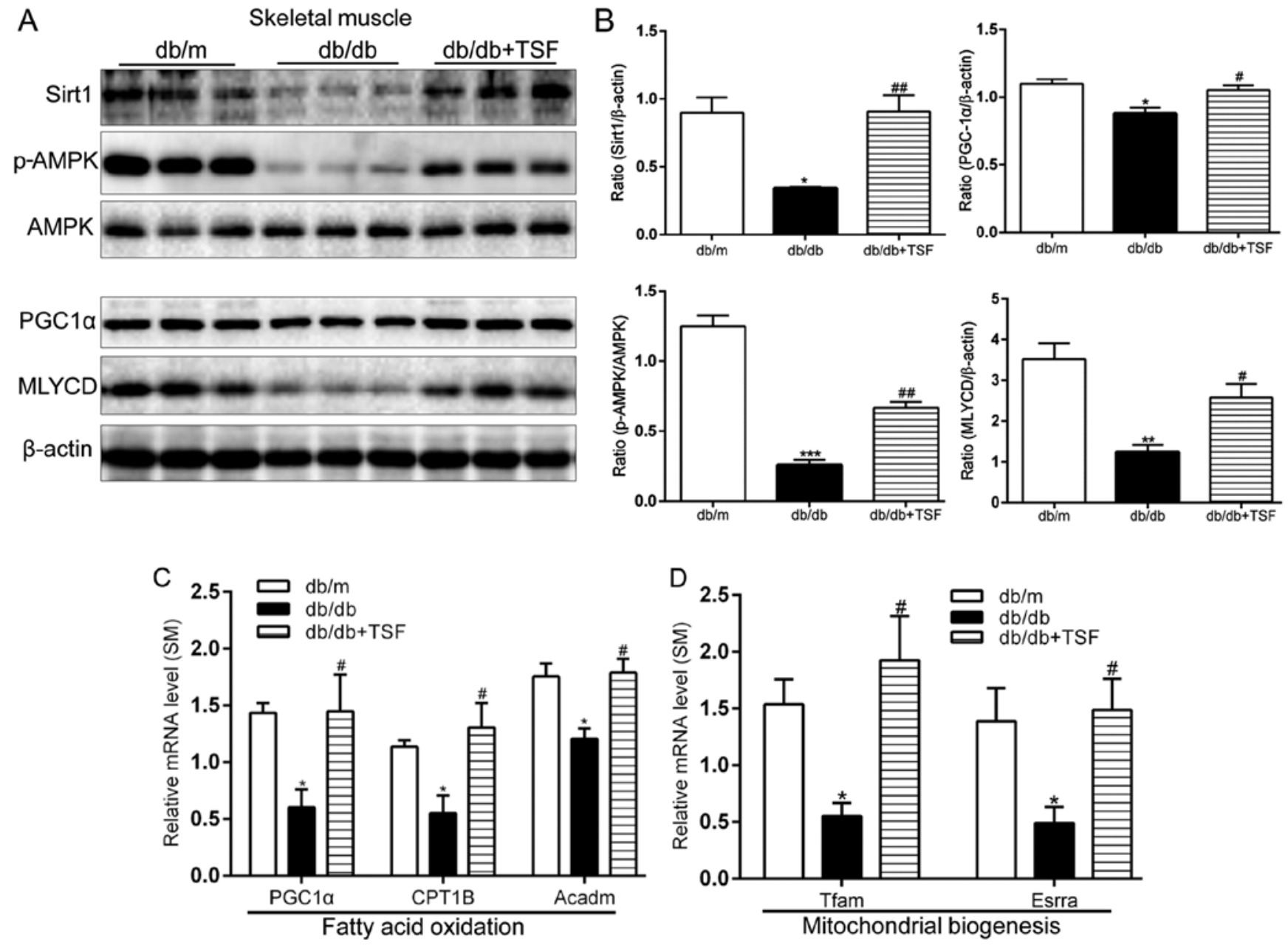

Figure 6. Tangshen formula (TSF) stimulates the phosphorylation of AMP-activated protein kinase (AMPK), silent mating type information regulation 2 homolog 1 (Sirt1) and fatty acid oxidation in the skeletal muscle of db/db mice. (A) Skeletal muscle Sirt1, p-AMPK, PPAR $\gamma$ co-activator (PGCl $\alpha$ ) and malonylCoA decarboxylase (MLYCD) were analyzed by western blot analysis and (B) semi-quantitative analysis. (C) Expression of genes involved in fatty acid oxidation and (D) mitochondrial biogenesis. Data are presented as the means \pm SEM. ${ }^{*} \mathrm{P}<0.05,{ }^{* *} \mathrm{P}<0.01$ and ${ }^{* * * *} \mathrm{P}<0.001 \mathrm{vs}$. db/m group; ${ }^{*} \mathrm{P}<0.05$ and ${ }^{\# \#} \mathrm{P}<0.01 \mathrm{vs}$. db/db group.

of $\mathrm{db} / \mathrm{db}$ mice (Fig. 5B). Moreover, the mRNA expression levels of genes that were assayed by RT-qPCR were consistent with the protein expression results (Fig. 5C). Treatment with TSF also increased the expression of genes involved in fatty acid oxidation, such as medium-chain acyl-CoA dehydrogenase (Acadm) and acyl-CoA oxidase (Acox1) (Fig. 5C). Peripheral fatty acids contribute to the accumulation of hepatic triglyceride in NAFLD; lipoprotein lipase (LPL) and the fatty acid translocase CD36 (FAT/CD36) are involved in the transport of fatty acids to the liver (29). Accordingly, we detected a significant downregulation in the levels of both LPL and FAT/CD36 in the livers of $\mathrm{db} / \mathrm{db}$ mice treated with TSF (Fig. 5D).

Sirt1 and AMPK are critical regulators in metabolic tissues, particularly in skeletal muscle as energy sensors (30). We also found that TSF increased the expression of hepatic Sirtl and p-AMPK, as well as that of their target proteins, PGCl $\alpha$ and MLYCD, that was in keeping with similar findings in the skeletal muscle of $\mathrm{db} / \mathrm{db}$ mice (Fig. 6A and B). In addition, TSF markedly enhanced the expression of genes involved in fatty acid oxidation, such as Acadm and CPT1B (Fig. 6C). In addition, mitochondrial biogenesis was enhanced in skeletal muscle, as reflected by the upregulation of genes and mito- chondrial transcription factor A (Tfam) and estrogen-related receptor- $\alpha$ (Esrra) (Fig. 6D).

Effect of TSF on the PI3K/Akt/mTOR cascade and gluconeogenesis in the livers of db/db mice. The expression of PI3K and the phosphorylation of Akt were significantly enhanced in the $\mathrm{db} / \mathrm{db}$ mice that were administered TSF. An important finding is that treatment with TSF caused a marked decrease in the expression of p-mTOR (Fig. 7A and B). Moreover, the administration of TSF substantially decreased the expression of genes involved in hepatic gluconeogenesis, such as glucose-6-phosphatase (G6pc) and phosphoenolpyruvate carboxykinase 1 (Pck1) (Fig. 7C). In concordance with these findings, we found that strong hepatic glycogen accumulated in the $\mathrm{db} / \mathrm{db}$ mice treated with TSF (Fig. 7D). These results point to a participation of these genes in the regulation of glucose and lipid homeostasis by TSF in NAFLD.

\section{Discussion}

Our study provides evidence that TSF diminishes body weight gain, reduces lipid accumulation in the liver and improves lipid profiles in $\mathrm{db} / \mathrm{db}$ mice. TSF stimulates AMPK activity and 

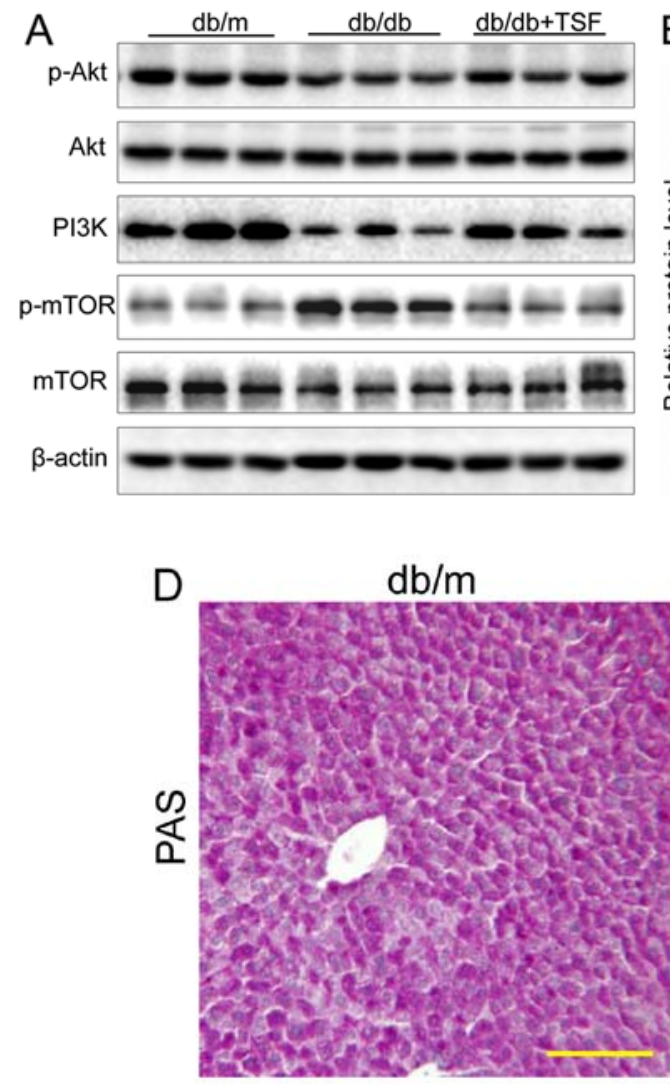

B

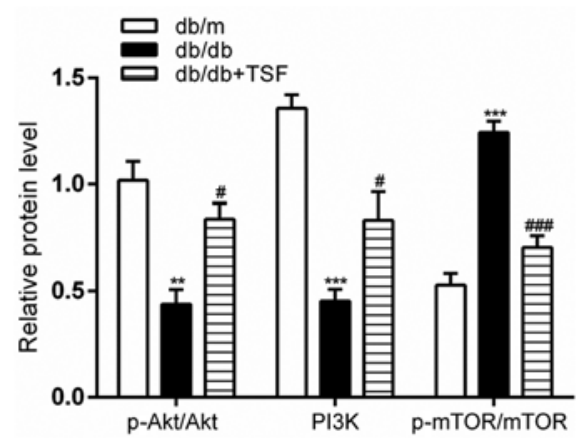

C

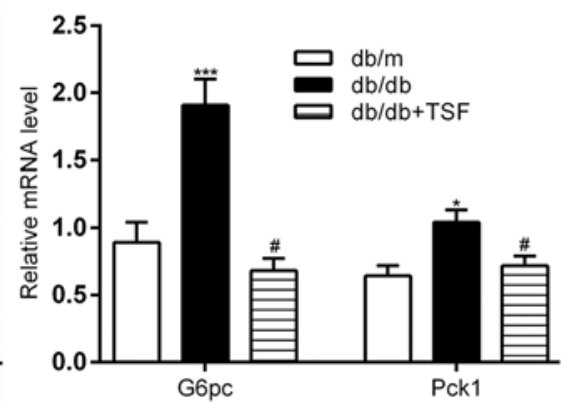

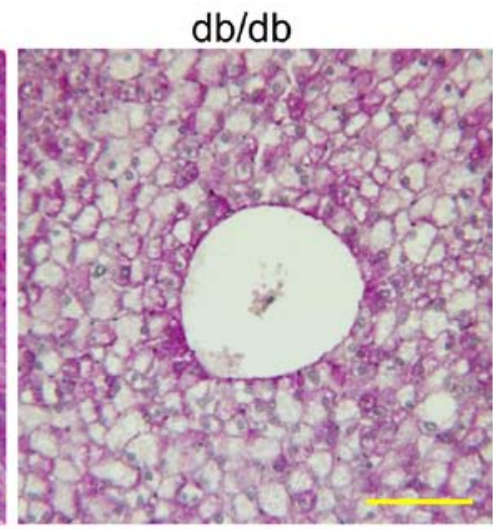

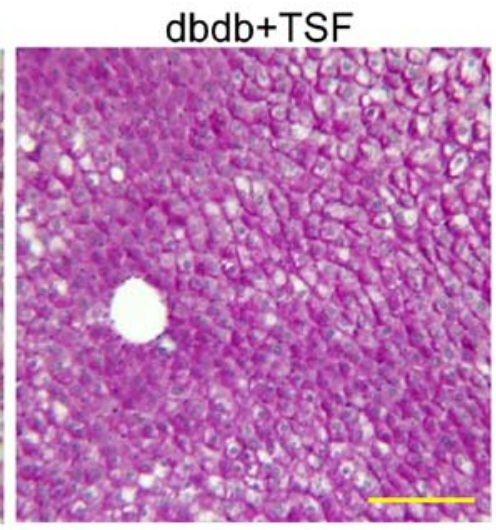

Figure 7. Tangshen formula (TSF) treatment induces the phosphorylation of Akt and mammalian target of rapamycin (mTOR) and restores glycogen deposition (A) TSF induced the upregulation of PI3K, p-Akt and blunted the phosphorylation of mTOR and (B) semi-quantitative analysis. (C) TSF regulated the expression of the glucose-6-phosphatase (G6pc) and phosphoenolpyruvate carboxykinase 1 (Pck1) genes in the livers of db/db mice. (D) Representative photomicrographs of PAS staining shows glycogen deposition in the livers of $\mathrm{db} / \mathrm{db}$ mice treated with TSF. Scale bar, $100 \mu \mathrm{m}$. Data are presented as the means \pm SEM. "P $<0.05$, ${ }^{* *} \mathrm{P}<0.01$ and ${ }^{* * * *} \mathrm{P}<0.001$ vs. db/m group; ${ }^{\#} \mathrm{P}<0.05$ and ${ }^{\# \# \#} \mathrm{P}<0.001$ vs. db/db group.<smiles>COC(=O)C1=COC(OC2OC(CO)C(O)C(O)C2O)C2CC(O)C(C)C12</smiles><smiles>COc1ccc(C2CC(=O)c3c(O)cc(OC4OC(CO)[C@@H](O)[C@H](O)[C@H]4OC4O[C@H](C)[C@@H](O)[C@H](O)[C@H]4O)cc3O2)cc1O</smiles>

B<smiles>COc1ccc(-c2coc3cc(OC4OC(CO)[C@H](O)[C@H](O)C4O)ccc3c2=O)cc1O</smiles>

C<smiles>C[C@H]1OC(OC2OC(Oc3cc(O)c4c(c3)OC(c3ccc(O)cc3)CC4=O)C(O)[C@@H](O)[C@H]2O)[C@H](O)[C@H](O)[C@@H]1O</smiles>

$\mathrm{E}$<smiles>O=C1CC(c2ccc(O)cc2)Oc2cc(O)cc(O)c21</smiles>

$\mathrm{F}$<smiles>O=C1c2cc(CO)cc(O)c2C(=O)c2cccc(O)c21</smiles>

Figure 8. Representative compounds identified in Tangshen formula (TSF) by high performance liquid chromatography (HPLC). HPLC chemical fingerprint chromatogram of TSF including (A) loganin (PubChem CID: 87691), (B) calycosin-7-O- $\beta$-D-glucoside (PubChem CID: 442813), (C) naringenine-7-rhamnosidoglucoside (PubChem CID: 25075), (D) neohesperidin (PubChem CID: 442439), (E) naringenin (PubChem CID: 932), (F) Aloe-emodin (PubChem CID: 10207).

blocks SREBP1 transcriptional and cleavage activity, which results in a variety of metabolic effects. These include the reduced expression of genes involved in fatty acid combustion and the increased expression of genes involved in lipogenesis. 
Most importantly, these data are in keeping with our findings that TSF prominently blunts hepatic lipogenesis and gluconeogenesis, enhances fatty acid oxidation and regulates energy balance in skeletal muscle.

Hepatic lipid accumulation is the most prominent characteristic of NAFLD in various stages, involving DNL, lipid transport and oxidation pathways in the liver. In this study, in both the liver and skeletal tissues, alterations in lipid metabolism by TSF were accompanied by AMPK activation, which leads to energy-consuming pathways, such as fatty acid synthesis and gluconeogenesis, being inhibited, and energy-generating pathways, such as fatty acid oxidation and glycolysis, being activated. Additionally, TSF increased the gene expression of AdipoR1 and AdipoR2 in the liver, reflecting that the level of adiponectin was elevated. Adiponectin, an 'anti-diabetic' adipokine, has been reported to have beneficial effects on lipid metabolism via AMPK and PPAR $\alpha(31,32)$.

AMPK also regulates the activity of ACC, a well characterized target gene of AMPK and SREBP1, by modulating its inhibitory phosphorylation (33). ACC is an essential lipogenic enzyme that blunts FFA oxidation and initiates DNL by increasing the levels of malonyl-CoA, an inhibitor of CPT1. CPT1 is an crucial enzyme that controls the flow of fatty acid to mitochondrial $\beta$-oxidation (34). Our data demonstrated that TSF markedly activated the AMPK-mediated the phosphorylation of ACC. In addition, TSF decreased the expression of target genes of AMPK or SREBP1 (FAS, SCD1 and HMGCR), which demonstrated a significant reduction in both the mRNA and protein levels. These data demonstrate that TSF activated the phosphorylation of AMPK and suppressed the nuclear translocation of SREBP1 in the liver, thus blunting the genes involved in lipogenesis by translational modifications.

AMPK regulates SREBP1 activity and inhibits lipogenesis in part via the inhibition of mTOR in the fatty liver $(19,35)$. mTOR signaling has been shown to regulate lipid metabolic processes, including DNL and triglyceride synthesis $(36,37)$. With overfeeding and obesity, liver mTOR activity is elevated, leading to gluconeogenesis and lipogenesis (38). We found that the expression of p-mTOR was significantly enhanced in the $\mathrm{db} / \mathrm{db}$ mice and was suppressed by the administration of TSF. More importantly, we demonstrated that impaired hepatic PI3K/Akt signaling caused by obesity in $\mathrm{db} / \mathrm{db}$ mice was restored by TSF, reflecting that TSF enhanced insulin sensitivity in NAFLD. Increased glycogen accumulation and the decreased gene expression of gluconeogenesis in the liver were in accordance with this observation. Notably, the plasma glucose levels were not decreased in the $\mathrm{db} / \mathrm{db}$ mice treated with TSF. These results indicate that TSF promotes hepatic glycogen gathered mainly from other pathways, but not plasma glucose. Hepatic steatosis is commonly associated with obesity, insulin resistance and hyperlipidemia (39). We found that treatment with TSF enhanced insulin sensitivity in fatty liver, which may partially be due to changes in hepatic lipid profiles. Taken together, these findings suggest that TSF exerts its beneficial effects on hepatic steatosis and insulin resistance related to obesity, at least partially through the regulation of the AMPK/ mTOR/SREBP1 axis.

As is known, hepatic lipid accumulation of NAFLD is closely related to lipid transport. This metabolic process may be mediated partially by the regulation of FAT/CD36 and
LPL (40). The overexpression of FAT/CD36 increases fatty acid and triglyceride storage in the livers of high-fat induced obesity mice (41). In this study, we found that treatment with TSF decreased the expression of the FAT/CD36 and LPL genes, indicating that TSF attenuated hepatic steatosis, in part by regulating liver lipid transport.

It should be noted that ameliorating hepatic steatosis by aggravating fatty acid oxidation is an alternative strategy. In our experiments, we found that several genes involved in FFA oxidation were mediated in the liver and skeletal muscle by treatment with TSF. Sirt1 has been implicated in modulating cellular metabolism and facilitating fatty acid utilization followed by eliminating fat ectopic accumulation (30). The mechanisms through which Sirtl activation attenuates hepatic steatosis include the inactivation of SREBP1 and the activation of PGC1 $\alpha$. The latter pathway may increase MLYCD expression, a target of PPAR $\alpha$ (42). Additionally, PPAR $\alpha$ is the common target gene of AMPK and Sirt1, and is centrally involved in fatty acid $\beta$-oxidation (43). Finally, Sirt1 leads to decreased hepatic malonyl-CoA, accelerates FFA oxidation and attenuates hepatic steatosis. Moreover, Sirt1 promotes mitochondrial biogenesis via the activation of PGC1 $\alpha$, by which FFA oxidation and mitochondrial biogenesis are driven. In this study, we found that TSF markedly increased Sirt1, PGC1 $\alpha$ and PPAR $\alpha$ expression in the liver and skeletal muscle of $\mathrm{db} /$ $\mathrm{db}$ mice. Accordingly, mitochondrial biogenesis was enhanced by TSF, reflected by the upregulated expression of genes involved in mitochondrial function (Tfam and Esrra). These findings demonstrate that TSF activated the Sirt1/PPAR $\alpha$ / MLYCD pathway and improved CPT1 activity to enhance the mitochondrial oxidation of fatty acid.

In conclusion, the present study demonstrates that TSF improved lipid profiles and attenuated hepatic steatosis in $\mathrm{db} /$ $\mathrm{db}$ mice. The inhibition of lipogenesis and the augmentation of fatty acid oxidation in the liver and skeletal muscle may be the underlying mechanisms throught which TSF improves diabetes-associated liver injury.

\section{Acknowledgements}

This study was funded by the National Natural Science Foundation of China (grant nos. 81130066 and 81473526); the International S\&T Cooperation Program of China (grant no. 2011DFA31860); the Beijing Municipal Science and Technology Program (grant no. Z151100003815015). The authors would like to thank Ms. (Pamir Communications, Daly City, CA, USA) Nissi S. Wang for providing editorial assistance with the manuscript.

\section{References}

1. Smyth S and Heron A: Diabetes and obesity: The twin epidemics. Nat Med 12: 75-80, 2006

2. Loomba R and Sanyal AJ: The global NAFLD epidemic. Nat Rev Gastroenterol Hepatol 10: 686-690, 2013.

3. Ruderman NB, Carling D, Prentki M and Cacicedo JM: AMPK, insulin resistance, and the metabolic syndrome. J Clin Invest 123: 2764-2772, 2013

4. Fu L, Bruckbauer A, Li F, Cao Q, Cui X, Wu R, Shi H, Zemel MB and Xue B: Interaction between metformin and leucine in reducing hyperlipidemia and hepatic lipid accumulation in dietinduced obese mice. Metabolism 64: 1426-1434, 2015. 
5. Lian Z, Li Y, Gao J, Qu K, Li J, Hao L, Wu S and Zhu H: A novel AMPK activator, WS070117, improves lipid metabolism discords in hamsters and HepG2 cells. Lipids Health Dis 10: 67, 2011.

6. Lee JH, Jung JY, Jang EJ, Jegal KH, Moon SY, Ku SK, Kang SH, Cho IJ, Park SJ, Lee JR, et al: Combination of honokiol and magnolol inhibits hepatic steatosis through AMPK-SREBP-1 c pathway. Exp Biol Med (Maywood) 240: 508-518, 2015.

7. Jeon TI and Osborne TF: SREBPs: Metabolic integrators in physiology and metabolism. Trends Endocrinol Metab 23: 65-72, 2012.

8. Han J, Li E, Chen L, Zhang Y, Wei F, Liu J, Deng H and Wang Y: The CREB coactivator CRTC2 controls hepatic lipid metabolism by regulating SREBP1. Nature 524: 243-246, 2015.

9. Ponugoti B, Kim DH, Xiao Z, Smith Z, Miao J, Zang M, Wu SY, Chiang CM, Veenstra TD and Kemper JK: SIRT1 deacetylates and inhibits SREBP-1C activity in regulation of hepatic lipid metabolism. J Biol Chem 285: 33959-33970, 2010.

10. Hou X, Xu S, Maitland-Toolan KA, Sato K, Jiang B, Ido Y, Lan F, Walsh K, Wierzbicki M, Verbeuren TJ, et al: SIRT1 regulates hepatocyte lipid metabolism through activating AMP-activated protein kinase. J Biol Chem 283: 20015-20026, 2008.

11. Musso G, Gambino R and Cassader M: Emerging molecular targets for the treatment of nonalcoholic fatty liver disease. Annu Rev Med 61: 375-392, 2010.

12. Zhang H, Li P, Burczynski FJ, Gong Y, Choy P, Sha H and Li J: Attenuation of diabetic nephropathy in Otsuka Long-Evans Tokushima Fatty (OLETF) rats with a combination of Chinese Herbs (Tangshen Formula). Evid Based Complement Alternat Med 2011: 613737, 2011.

13. Huang M: C.Z,Liang QL, Li P, Li J, Wang YM and Luo GA: Effect of Tangshen Formula on phospholipids metabolism in diabetic nephropathy patients. Acta Pharmacol Sin 46: 780-786, 2011.

14. Tiniakos DG, Vos MB and Brunt EM: Nonalcoholic fatty liver disease: Pathology and pathogenesis. Annu Rev Pathol 5: 145-171, 2010.

15. Li P, Chen Y, Liu J, Hong J, Deng Y, Yang F, Jin X, Gao J, Li J, Fang $\mathrm{H}$, et al: Efficacy and safety of tangshen formula on patients with type 2 diabetic kidney disease: A multicenter double-blinded randomized placebo-controlled trial. PLoS One 10: e0126027, 2015.

16. Reagan-Shaw S, Nihal M and Ahmad N: Dose translation from animal to human studies revisited. FASEB J 22: 659-661, 2008.

17. Brunt EM, Janney CG, Di Bisceglie AM, Neuschwander-Tetri BA and Bacon BR: Nonalcoholic steatohepatitis: A proposal for grading and staging the histological lesions. Am J Gastroenterol 94 2467-2474, 1999.

18. Sun SF, Zhao TT, Zhang HJ, Huang XR, Zhang WK, Zhang L, Yan MH, Dong X, Wang H, Wen YM, et al: Renoprotective effect of berberine on type 2 diabetic nephropathy in rats. Clin Exp Pharmacol Physiol 42: 662-670, 2015.

19. Quan HY, Kim Y, Kim SJ, Jo HK, Kim GW and Chung SH: Betulinic acid alleviates non-alcoholic fatty liver by inhibiting SREBP1 activity via the AMPK-mTOR-SREBP signaling pathway. Biochem Pharmacol 85: 1330-1340, 2013.

20. Schmittgen TD and Livak KJ: Analyzing real-time PCR data by the comparative C(T) method. Nat Protoc 3: 1101-1108, 2008.

21. Castaño D, Larequi E, Belza I, Astudillo AM, Martínez-Ansó E, Balsinde J, Argemi J, Aragon T, Moreno-Aliaga MJ, Muntane J, et al: Cardiotrophin-1 eliminates hepatic steatosis in obese mice by mechanisms involving AMPK activation. J Hepatol 60 : 1017-1025, 2014

22. Jung EJ, Kwon SW, Jung BH, Oh SH and Lee BH: Role of the AMPK/SREBP-1 pathway in the development of orotic acidinduced fatty liver. J Lipid Res 52: 1617-1625, 2011.

23. Li Y, Xu S, Mihaylova MM, Zheng B, Hou X, Jiang B, Park O, Luo Z, Lefai E, Shyy JY, et al: AMPK phosphorylates and inhibits SREBP activity to attenuate hepatic steatosis and atherosclerosis in diet-induced insulin-resistant mice. Cell Metab 13: 376-388, 2011

24. Purushotham A, Schug TT, Xu Q, Surapureddi S, Guo X and Li X: Hepatocyte-specific deletion of SIRT1 alters fatty acid metabolism and results in hepatic steatosis and inflammation. Cell Metab 9: 327-338, 2009

25. Grefhorst A, Elzinga BM, Voshol PJ, Plösch T, Kok T, Bloks VW, van der Sluijs FH, Havekes LM, Romijn JA, Verkade HJ and Kuipers F: Stimulation of lipogenesis by pharmacological activation of the liver $\mathrm{X}$ receptor leads to production of large triglyceride-rich very low density lipoprotein particles. J Bio Chem 277: 34182-34190, 2002.
26. Sim WC, Park S, Lee KY, Je YT, Yin HQ, Choi YJ, Sung SH, Park SJ, Park HJ, Shin KJ and Lee BH: LXR- $\alpha$ antagonist meso-dihydroguaiaretic acid attenuates high-fat diet-induced nonalcoholic fatty liver. Biochem Pharmacol 90: 414-424, 2014.

27. Foster DW: Malonyl-CoA: the regulator of fatty acid synthesis and oxidation. J Clin Invest 122: 1958-1959, 2012.

28. Derdak Z, Villegas KA, Harb R, Wu AM, Sousa A and Wands JR: Inhibition of p53 attenuates steatosis and liver injury in a mouse model of non-alcoholic fatty liver disease. J Hepatol 58: 785-791, 2013.

29. Wang C, Hu L, Zhao L, Yang P, Moorhead JF, Varghese Z, Chen Y and Ruan XZ: Inflammatory stress increases hepatic CD36 translational efficiency via activation of the mTOR signalling pathway. PLoS One 9: e103071, 2014.

30. Price NL, Gomes AP, Ling AJ, Duarte FV, Martin-Montalvo A, North BJ, Agarwal B, Ye L, Ramadori G, Teodoro JS, et al: SIRT1 is required for AMPK activation and the beneficial effects of resveratrol on mitochondrial function. Cell Metab 15: 675-690, 2012.

31. Yamauchi T, Kamon J, Waki H, Imai Y, Shimozawa N, Hioki K, Uchida S, Ito Y, Takakuwa K, Matsui J, et al: Globular adiponectin protected ob/ob mice from diabetes and ApoE-deficient mice from atherosclerosis. J Biol Chem 278: 2461-2468, 2003.

32. Yamauchi T, Kamon J, Minokoshi Y, Ito Y, Waki H, Uchida S, Yamashita S, Noda M, Kita S, Ueki K, et al: Adiponectin stimulates glucose utilization and fatty-acid oxidation by activating AMP-activated protein kinase. Nat Med 8: 1288-1295, 2002.

33. Moreno-Aliaga MJ, Pérez-Echarri N, Marcos-Gómez B, Larequi E, Gil-Bea FJ, Viollet B, Gimenez I, Martínez JA, Prieto J and Bustos M: Cardiotrophin-1 is a key regulator of glucose and lipid metabolism. Cell Metab 14: 242-253, 2011.

34. McGarry JD, Mannaerts GP and Foster DW: A possible role for malonyl-CoA in the regulation of hepatic fatty acid oxidation and ketogenesis. J Clin Invest 60: 265-270, 1977.

35. Zhang J, Zhang LN, Chen DM, Fu YY, Zhang F, Yang LL, Xia CM, Jiang HW, Tang CL, Xie ZF, et al: 2-(3-Benzoylthioureido)-4,5,6,7tetrahydrobenzo[b]thiophene-3-carboxylic acid ameliorates metabolic disorders in high-fat diet-fed mice. Acta Pharmacol Sin 36: 483-496, 2015.

36. Lamming DW and Sabatini DM: A Central role for mTOR in lipid homeostasis. Cell Metab 18: 465-469, 2013.

37. Soliman GA: The integral role of mTOR in lipid metabolism. Cell Cycle 10: 861-862, 2011.

38. Yecies JL, Zhang HH, Menon S, Liu S, Yecies D, Lipovsky AI, Gorgun C, Kwiatkowski DJ, Hotamisligil GS, Lee CH and Manning BD: Akt stimulates hepatic SREBP1c and lipogenesis through parallel mTORC1-dependent and independent pathways. Cell Metab 14: 21-32, 2011.

39. Birkenfeld AL and Shulman GI: Nonalcoholic fatty liver disease, hepatic insulin resistance, and type 2 diabetes. Hepatology 59: 713-723, 2014.

40. Donnelly KL, Smith CI, Schwarzenberg SJ, Jessurun J, Boldt MD and Parks EJ: Sources of fatty acids stored in liver and secreted via lipoproteins in patients with nonalcoholic fatty liver disease. J Clin Invest 115: 1343-1351, 2005.

41. Koonen DP, Jacobs RL, Febbraio M, Young ME, Soltys CL, Ong H, Vance DE and Dyck JR: Increased hepatic CD36 expression contributes to dyslipidemia associated with dietinduced obesity. Diabetes 56: 2863-2871, 2007.

42. Lee GY, Kim NH, Zhao ZS, Cha BS and Kim YS: Peroxisomalproliferator-activated receptor alpha activates transcription of the rat hepatic malonyl-CoA decarboxylase gene: A key regulation of malonyl-CoA level. Biochem J 378: 983-990, 2004.

43. Zhu LH, Wang A, Luo P, Wang X, Jiang DS, Deng W, Zhang X, Wang T, Liu Y, Gao L, et al: Mindin/Spondin 2 inhibits hepatic steatosis, insulin resistance, and obesity via interaction with peroxisome proliferator-activated receptor $\alpha$ in mice. J Hepatol 60: $1046-1054,2014$ 